\title{
Palladium Supported on Bis(indolyl)methane Functionalized Magnetite Nanoparticles as an Efficient Catalyst for Copper-Free Sonogashira-Hagihara Reaction
}

\author{
Mohammad Gholinejad, ${ }^{* a}$ Abdollah Neshat, ${ }^{* a}$ Fatemeh Zareh, ${ }^{a}$ Carmen Nájera ${ }^{\mathrm{b}}$, Mehran \\ Razeghi, ${ }^{a}$ Abbas Khoshnood ${ }^{b}$
}

\begin{abstract}
${ }^{\text {a }}$ Department of Chemistry, Institute for Advanced Studies in Basic Sciences (IASBS), P. O. Box 45195-1159, Gava zang, Zanjan 45137-6731, Iran.

Email: gholinejad@iasbs.ac.ir; a.neshat@iasbs.ac.ir
b Departamento de Química Orgánica and Centro de Innovación en Química Avanzada (ORFEO- CINQA). Universidad de Alicante, Apdo. 99, E-03080-Alicante, Spain

\begin{abstract}
A novel heterogeneous catalyst based on palladium nanoparticles supported on 3,3'-bisindolyl(4hydroxyphenyl)methane functionalized magnetite $\left(\mathrm{Fe}_{3} \mathrm{O}_{4}\right)$ nanoparticles was synthesized, characterized and used as catalyst for Sonogashira-Hagihara reaction. The alkynylation of a variety of aryl iodides and aryl bromides with terminal alkynes was carried out at $60{ }^{\circ} \mathrm{C}$ under copper and phosphane-free conditions using $N, N$-dimethyl acetamide as solvent, DABCO as base and low Pd loadings $(0.18 \mathrm{~mol} \%)$ under air. In the case of aryl chlorides, the reaction was carried out at 120 ${ }^{\circ} \mathrm{C}$ in the presence of tetra- $n$-butylammonium bromide (TBAB) and $0.36 \mathrm{~mol} \%$ of Pd catalyst. The heterogeneous palladium catalyst introduced in this study is recoverable by an external magnet and it can be used for seven consecutive runs without a significant loss in catalytic activity.
\end{abstract}


Keywords: Magnetic, Palladium, Nanoparticles, Sonogashira, Copper-free

\section{Introduction}

The palladium catalyzed carbon-carbon bond forming reactions are of great importance in modern synthetic organic chemistry [1]. Among well-known carbon-carbon coupling reactions, the Sonogashira-Hagihara cross-coupling stands out as a unique method enabling the coupling between $(\mathrm{sp})$ carbon and $\left(\mathrm{sp}^{2}\right)$ carbon atoms [2-9]. The reaction products containing such bonds have found applications in a wide range of synthetic reactions such as biologically active compounds and pharmaceuticals [10-12]. Palladium catalyzed Sonogashira-Hagihara alkynylation reaction can be performed either in the presence of copper as co-catalyst or under copper-free conditions. The presence of copper increases the reactivity of the acetylene by the formation of a copper acetylide. However, the formation of undesired homo-coupling byproducts is usually observed (Glaser coupling reaction) [13-14]. Thus, the design and synthesis of active palladium catalysts for Sonogashira-Hagihara reaction under copper free and mild reaction conditions are highly desirable [15-24].

Due to difficulties in the removal of metal contaminants of coupling reaction products under homogeneous conditions, many heterogeneous palladium catalysts for Sonogashira-Hagihara reaction have also been developed in recent years [2, 25-29]. However, despite great developments in this field, heterogeneous catalysts are also difficult to separate from the reaction mixture by standard laboratory methods such as filtration and centrifugation. In this regard, magnetic nanoparticles with large ratio of surface area to volume, superparamagnetic behavior and low toxicity have proven to be an excellent supports for the stabilization of palladium nanoparticles (NPs) [30-36]. Variety of ligands such as those containing phosphane 
or nitrogen functional groups have been used for the modification of $\mathrm{Fe}_{3} \mathrm{O}_{4}$ nanoparticles. However, phosphane-based ligands are air and/or moisture sensitive, poisonous, unrecoverable and degradable at elevated temperatures which limits their large scale application in industrial level chemistry [37-39]. We have recently introduced two novel and efficient phosphane-free magnetic nanoparticles which supported palladium catalysts for Suzuki-Miyaura coupling reaction in water [40-41]. However, to date, a few magnetite nanoparticles supported palladium catalysts have been prepared and successfully used in the Sonogashira-Hagihara coupling reaction $[42-50]$.

We envisaged that supporting a 3,3'-bisindolyl(4-hydroxyphenyl)methane ligand to magnetite nanoparticles coated with silica gel would be an adequate and simple way to coordinate and stablize Pd nanoparticles. Herein, we report the synthesis of a new and highly active palladium catalyst supported on functionalized magnetite nanoparticles for Sonogashira-Hagihara reaction under copper and phosphane-free conditions.

\section{Experimental Section}

\subsection{General}

All chemicals were purchased from Sigma-Aldrich, Acros and Merck companies and were used without further purification. Magnetite $\left(\mathrm{Fe}_{3} \mathrm{O}_{4}\right)$ nanoparticles were prepared according to a previously reported method in the literature [51-52]. Synthesis of 3,3'-Bisindolyl(4hydroxyphenyl)methane was carried out by the modification of the published literature procedure [53]. ${ }^{1} \mathrm{H}$ and ${ }^{13} \mathrm{C}$ NMR spectra were recorded in $\mathrm{DMSO}-\mathrm{d}_{6}$ and $\mathrm{CDCl}_{3}$ at room temperature on a Bruker $400 \mathrm{MHz}$ spectrometer and referenced internally using TMS as internal standard. Thermogravimetric analysis (TGA) was conducted from room temperature to $700{ }^{\circ} \mathrm{C}$ in an oxygen, sure flow using a NETZSCH STA 409 PC/PG instrument. Transmission Electron 
Microscopy was carried out by JEOL model JEM-1400 Plus working at $120 \mathrm{kV}$ with a LaB6 filament. Magnetic measurements were performed using vibration sample magnetometry (VSM, (MDK Co. Kashan, Iran) analysis. FT-IR spectra were recorded on a Bruker Vector 22 instrument. Energy dispersive X-ray analysis (EDX) results were obtained using Carl Zeiss Sigma instrument. Adsorption-desorption analyses were recorded using BELsSORP-max instrument. The content of copper and palladium in the catalyst was determined using Varian atomic absorption spectrometry.

\subsection{Synthesis of silica-coated $\mathrm{Fe}_{3} \mathrm{O}_{4}$ nanoparticles (SMNP):}

$\mathrm{Fe}_{3} \mathrm{O}_{4}(1.0 \mathrm{~g})$ was sonicated in ethanol $(200 \mathrm{~mL})$ for $30 \mathrm{~min}$. at room temperature. Then, to the resulting suspension were added tetraethyl orthosilicate (TEOS, $2.0 \mathrm{~mL}$ ) and aqueous ammonia $(25 \%)(6.0 \mathrm{~mL})$ and the mixture was stirred for $24 \mathrm{~h}$ at room temperature. The obtained silicacoated $\mathrm{Fe}_{3} \mathrm{O}_{4}$ nanoparticles were separated by an external magnet and washed with distilled water $(3 \times 10 \mathrm{~mL})$ and ethanol $(3 \times 10 \mathrm{~mL})$ and dried under vacuum.

\subsection{Procedure for the preparation of $\mathrm{Cl} @ \mathrm{SiO}_{2} @ \mathrm{Fe}_{3} \mathrm{O}_{4}(1)$ :}

Dry SMNP powder $(1.0 \mathrm{~g})$ was mixed with dry toluene $(50 \mathrm{~mL})$ to produce a homogeneously mixed solution. This mixture was sonicated for $30 \mathrm{~min}$. prior to the addition of (3chloropropyl) trimethoxysilane $(7.0 \mathrm{mmol}, 1.27 \mathrm{~mL})$. The resulting mixture was refluxed for $24 \mathrm{~h}$ under argon atmosphere. Then, the reaction mixture was subjected to magnetic separation and the resulting powder was washed sequentially with distilled water $(3 \times 10 \mathrm{~mL})$ and ethanol $(3 \times 10 \mathrm{~mL})$ and finally dried under vacuum.

\subsection{Procedure for the preparation of compound (2):}


Compound $1(500 \mathrm{mg})$ was sonicated and dispersed separately in dry toluene $(20 \mathrm{~mL})$ for 30 min. In a separate experiment, sodium hydride $(1.2 \mathrm{mmol}, 27 \mathrm{mg})$ was added to prepared $3,3^{\prime}$ bisindolyl(4-hydroxyphenyl)methane $(1 \mathrm{mmol}, 330 \mathrm{mg})$ under argon and the resulting mixture was added to the flask containing compound 1 . The reaction mixture was stirred at $100{ }^{\circ} \mathrm{C}$ for $24 \mathrm{~h}$ under argon atmosphere. Then, the reaction mixture was cooled to room temperature and bis indole functionalized magnetic nanoparticles (2) were subjected to magnetic separation. The isolated product was washed sequentially with ethanol $(2 \times 10 \mathrm{~mL})$ and dried under vacuum for $24 \mathrm{~h}$.

\subsection{Procedure for the preparation of Pd@bisindole@ $\mathrm{SiO}_{2} @ \mathrm{Fe}_{3} \mathrm{O}_{4}$ :}

Compound $2(400 \mathrm{mg})$ was sonicated in dichloromethane $(10.0 \mathrm{~mL})$ for $30 \mathrm{~min}$. at room temperature. Then, $\mathrm{Pd}(\mathrm{OAc})_{2}(0.09 \mathrm{mmol}, 20 \mathrm{mg})$ was added and the mixture was stirred for $24 \mathrm{~h}$ at room temperature under argon atmosphere. Then, the reaction mixture was subjected to magnetic separation and the isolated material was washed sequentially with distilled water $(3 \times 10 \mathrm{~mL})$ and ethanol $(3 \times 10 \mathrm{~mL})$. Drying under vacuum for $24 \mathrm{~h}$ provided compound Pd@bisindole@ $\mathrm{SiO}_{2} @ \mathrm{Fe}_{3} \mathrm{O}_{4}$ as a black powder.

\subsection{General procedure for the Sonogashira-Hagihara reaction:}

Aryl halide and a terminal alkyne, with an equivalent molar ratio of 1.0 to 1.5 , were added to a mixture of Pd@ bisindole@ $\mathrm{SiO}_{2} @ \mathrm{Fe}_{3} \mathrm{O}_{4}(0.18$ mmol, $20 \mathrm{mg})$ and DABCO $(2.0 \mathrm{mmol}, 224 \mathrm{mg})$ in a flask and $2 \mathrm{~mL}$ DMA was added. The reaction mixture was stirred at $60{ }^{\circ} \mathrm{C}$ for aryl iodides and aryl bromides. The reaction temperature was set to $120^{\circ} \mathrm{C}$ for aryl chlorides and $1 \mathrm{mmol}$ TBAB was also added. The progress of the reaction was monitored by gas chromatography. After completion of the reaction, distilled water $(2 \mathrm{~mL})$ was added to the reaction mixture and 
the crude product was extracted with ethyl acetate $(3 \times 5.0 \mathrm{~mL})$. The crude product was further purified by column chromatography using n-hexane and ethyl acetate as eluents.

\section{Results and Discussion}

The catalyst preparation steps are summarized in Scheme 1. Briefly, $\mathrm{Fe}_{3} \mathrm{O}_{4}$ nanoparticles were prepared in a co-precipitation step based on the procedure of Massart et al. using $\mathrm{FeCl}_{3} \cdot 6 \mathrm{H}_{2} \mathrm{O}$ and $\mathrm{FeCl}_{2} .4 \mathrm{H}_{2} \mathrm{O}$ salts [51]. The obtained $\mathrm{Fe}_{3} \mathrm{O}_{4} \mathrm{NPs}$ were coated with a thin layer of silica using tetraethyl orthosilicate to produce core/shell $\mathrm{Fe}_{3} \mathrm{O}_{4}$ NPs (SMNP) [52]. The presence of a sharp peak in the IR spectrum around $1091 \mathrm{~cm}^{-1}$ (Figure 1, supporting information) confirmed the formation of Si-O-Fe bonds. $\mathrm{SiO}_{2} @ \mathrm{Fe}_{3} \mathrm{O}_{4}$ core/shell nanospheres were allowed to react with 3chloropropyltrimethoxysilane to afford chloro-functionalized magnetic NPs $\left(\mathrm{Cl} @ \mathrm{SiO}_{2} @ \mathrm{Fe}_{3} \mathrm{O}_{4}\right)$. In the next step, $\mathrm{NaH}$ was used as base to deprotonate the hydroxyl group of the prepared 3,3'-bisindolyl(4-hydroxyphenyl)methane. Then, $\mathrm{Cl} @ \mathrm{SiO}_{2} @ \mathrm{Fe}_{3} \mathrm{O}_{4}$ was added to afford 3,3'-bisindolyl(4-hydroxyphenyl)methane functionalized $\mathrm{Fe}_{3} \mathrm{O}_{4} \quad \mathrm{NPs}$ (bisindole@ $\mathrm{SiO}_{2} @ \mathrm{Fe}_{3} \mathrm{O}_{4} \mathrm{NPs}$ ). In the final step, the desired palladium-supported catalyst (3) was obtained by treating bisindole@ $\mathrm{SiO}_{2} @ \mathrm{Fe}_{3} \mathrm{O}_{4} \mathrm{NPs}$ with $\mathrm{Pd}(\mathrm{OAc})_{2}$ in dichloromethane at room temperature. The obtained material which is used as catalyst in this work is referred to as Pd@bisindole@ $\mathrm{SiO}_{2} @ \mathrm{Fe}_{3} \mathrm{O}_{4}$ throughout the text of this article.

Our initial goal was to test the reactivity of the bisindole@ $\mathrm{SiO}_{2} @ \mathrm{Fe}_{3} \mathrm{O}_{4} \mathrm{NPs}$ with $\mathrm{Pd}(\mathrm{OAc})_{2}$ to examine whether the bisindole unit of the nanoparticle can bind to palladium as a monodentate or bidentate ligand via the elimination of one or two acetic acid $(\mathrm{AcOH})$ molecules. However, we were surprised by the formation of palladium nanoparticles even in the absence of reducing agent such as $\mathrm{NaBH}_{4}$, which usually is a requirement for the reduction of $\mathrm{Pd}(\mathrm{II})$ species to $\operatorname{Pd}(0)$ 
prior to the formation of the metal nanoparticles. Therefore, understanding the mechanism of the formation of Pd@bisindole@ $\mathrm{SiO}_{2} @ \mathrm{Fe}_{3} \mathrm{O}_{4} \mathrm{NPs}$ (Scheme 1) in this study requires further analyses. We speculated that the presence of $\mathrm{N}-\mathrm{H}$ groups in the indole ring can stabilize palladium NPs, similar to ionic liquids with amide end-groups [54].

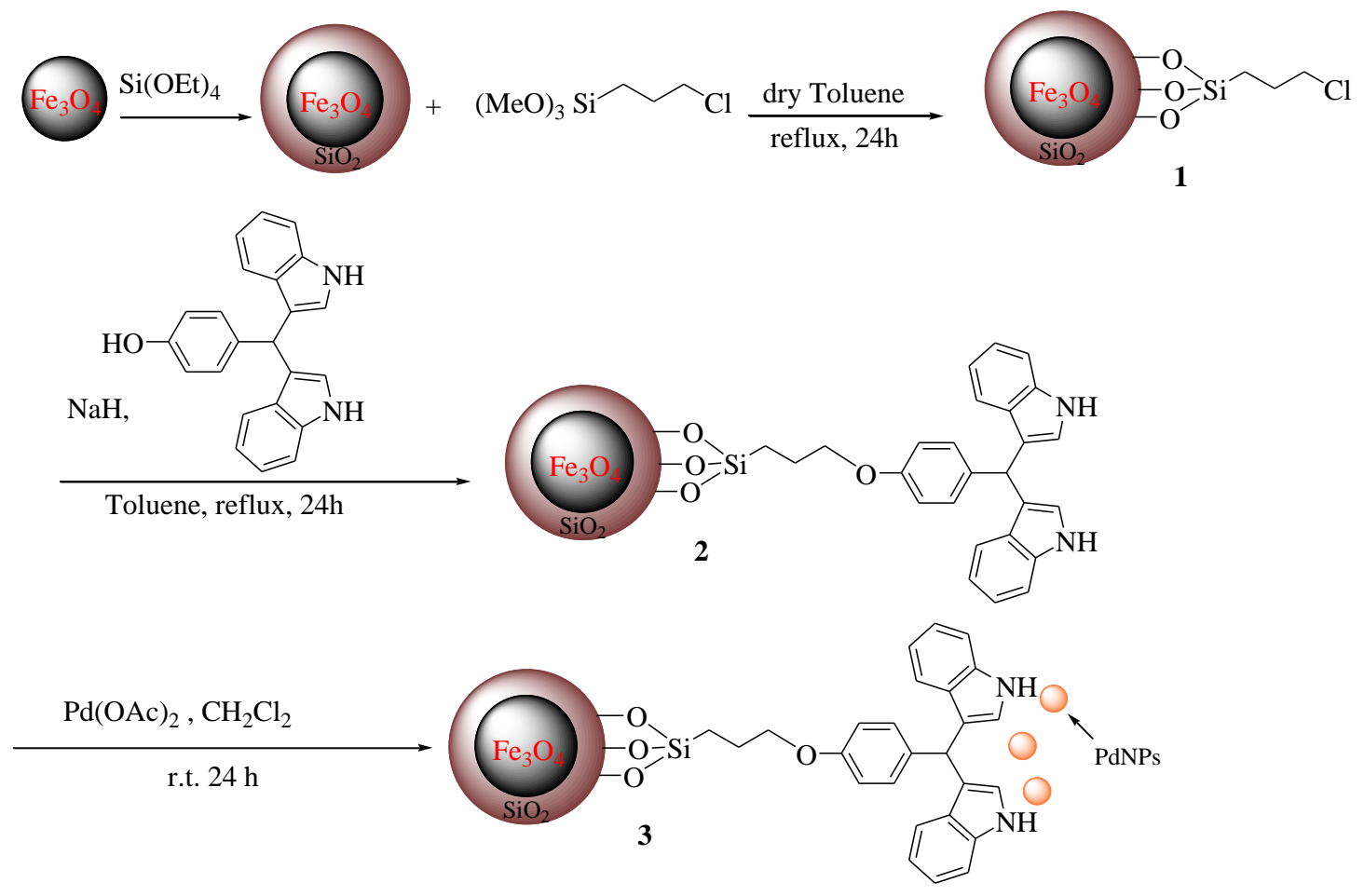

Scheme 1.Pd@ bisindole@ $\mathrm{SiO}_{2} @ \mathrm{Fe}_{3} \mathrm{O}_{4}$ preparation steps.

Thermogravimetric analysis was confirmed the formation of compound 1 showing two-step weight loss (Figure 1). First weight loss is related to water and physically adsorbed solvents and the second one is related to the organic residues attached to the surface of the support. 


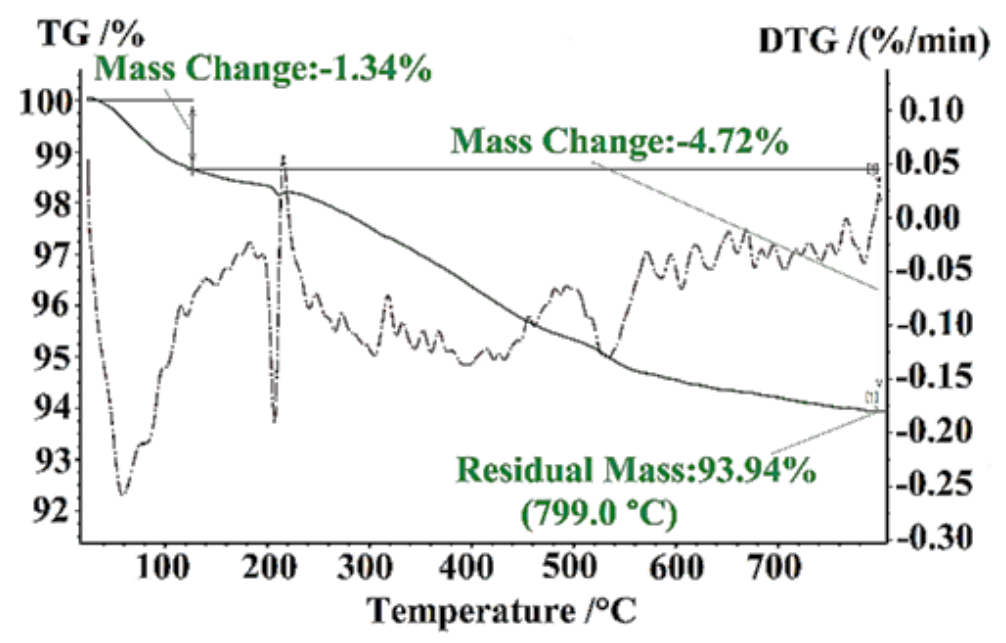

Figure 1. Thermogravimetric diagram of $\mathrm{Cl} @ \mathrm{SiO}_{2} @ \mathrm{Fe}_{3} \mathrm{O}_{4}$.

Moreover, thermogravimetric analysis of compound 2 showed an increase in loading which is probably related to the attaching of 3,3'-bisindolyl(4-hydroxyphenyl)methane to surface of compound 1 (Figure 2).

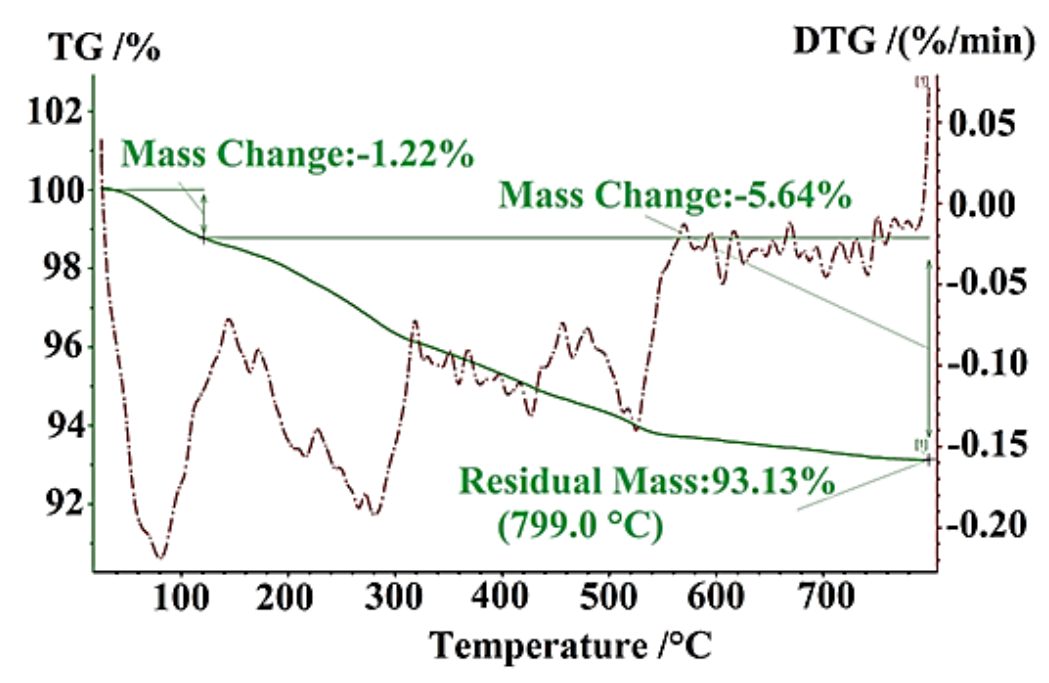

Figure 2. Thermogravimetric diagram of bisindole @ $\mathrm{SiO}_{2} @ \mathrm{Fe}_{3} \mathrm{O}_{4}$ nanoparticles.

Scanning electron microscopy (SEM) image of final Pd@bisindole@ $\mathrm{SiO}_{2} @ \mathrm{Fe}_{3} \mathrm{O}_{4}$ shows highly uniform particles (Figure 3). Furthermore, energy-dispersive X-ray spectroscopy (EDX) obtained 
from SEM shows the presence of $\mathrm{Pd}$ atoms as well as $\mathrm{N}, \mathrm{Fe}$, and $\mathrm{Si}$ atoms in the structure of compound Pd@bisindole@ $\mathrm{SiO}_{2} @ \mathrm{Fe}_{3} \mathrm{O}_{4}$ (Figure 4).

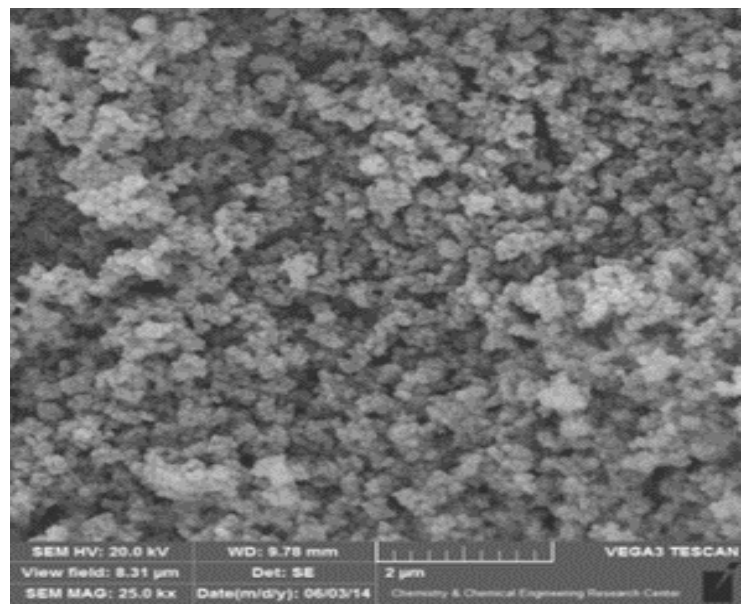

Figure 3. SEM image of $\mathrm{Pd} @$ bisindole@ $\mathrm{SiO}_{2} @ \mathrm{Fe}_{3} \mathrm{O}_{4}$

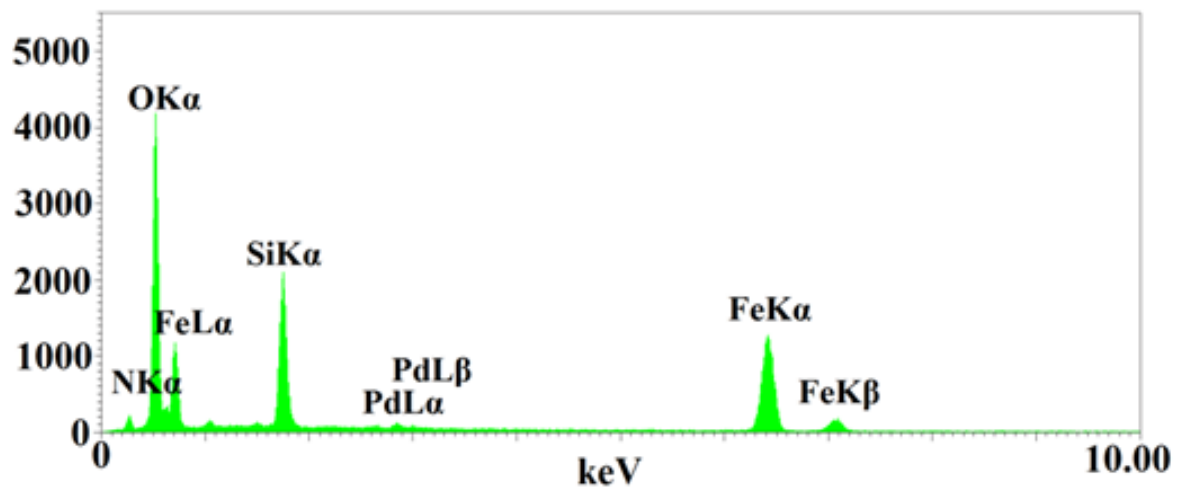

Figure 4. EDX diagram of $\mathrm{Pd} @$ bisindole@ $\mathrm{SiO}_{2} @ \mathrm{Fe}_{3} \mathrm{O}_{4}$.

X-ray photoelectron spectrum (XPS) of these palladium nanoparticles confirmed the presence of both $\operatorname{Pd}(0)$ and $\operatorname{Pd}(\mathrm{II})$ species in equal ratios by the appearance of two intensive doublets at 335 $\mathrm{eV}$ and $340 \mathrm{eV}$ related to $\mathrm{Pd}(0)$ and peaks at $337 \mathrm{eV}$ and $342 \mathrm{eV}$ related to $\mathrm{Pd}(\mathrm{II})$ corresponding to $\operatorname{Pd} 3 d_{5 / 2}$ and $P d 3 d_{3 / 2}$, respectively (Figure 5) [41,55]. 


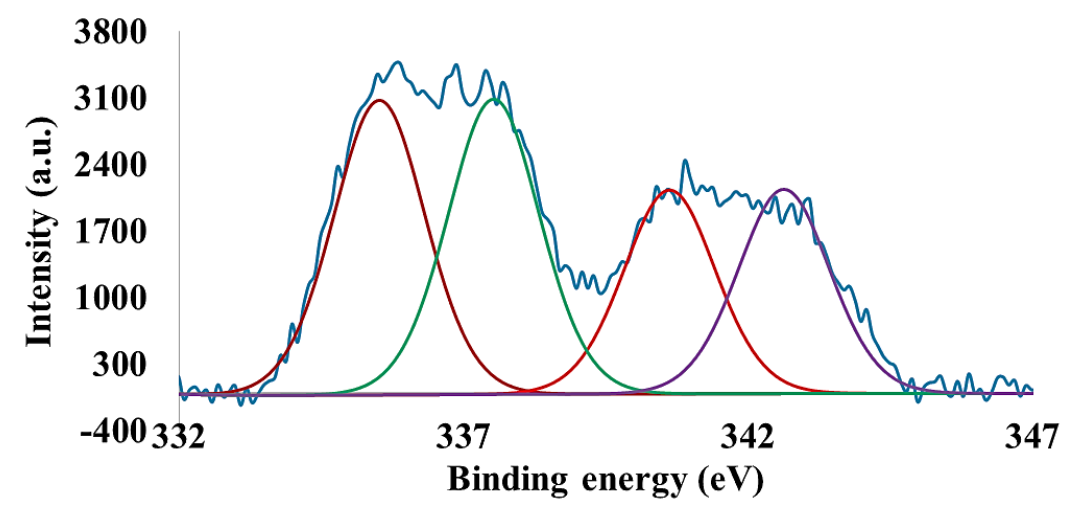

Figure 5. XPS spectrum of the Pd@bisindole@ $\mathrm{SiO}_{2} @ \mathrm{Fe}_{3} \mathrm{O}_{4}$.

High resolution transmission electron microscopy (HTEM) images show the presence of highly uniform and small size palladium nanoparticles in average size of $2 \mathrm{~nm}$ supported by 3,3'bisindolyl(4-hydroxyphenyl)methane functionalized $\mathrm{Fe}_{3} \mathrm{O}_{4}$ NPs (Figure 6). TEM images also show the average shell size of about $5 \mathrm{~nm}$ and $\mathrm{Fe}_{3} \mathrm{O}_{4} \mathrm{NPs}$ with an average size of $15 \mathrm{~nm}$.

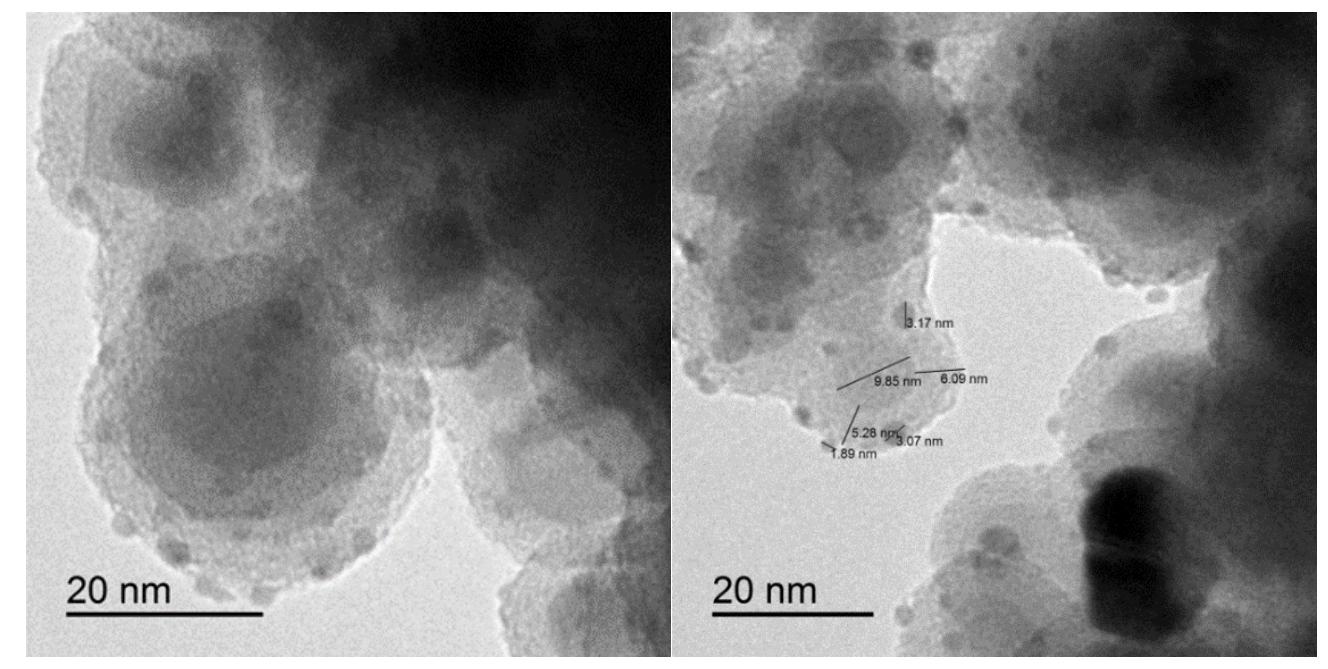

Figure 6. HTEM images of Pd@ bisindole@ $\mathrm{SiO}_{2} @ \mathrm{Fe}_{3} \mathrm{O}_{4}$.

We have also studied magnetization curves for $\mathrm{Fe}_{3} \mathrm{O}_{4} \quad \mathrm{NPs}, \quad \mathrm{SiO}_{2} @ \mathrm{Fe}_{3} \mathrm{O}_{4} \quad \mathrm{NPs}$, and $\mathrm{Pd} @$ bisindole@ $\mathrm{SiO}_{2} @ \mathrm{Fe}_{3} \mathrm{O}_{4}$ at room temperature (Figure 7). Results indicate that in all samples 
no hysteresis loop is observed, with both remanence and coercivity being zero, suggesting the superparamagnetic nature of the samples. It is worth mentioning that a decrease in the magnetization value of the $\mathrm{SiO}_{2} @ \mathrm{Fe}_{3} \mathrm{O}_{4}\left(39\right.$ emug $\left.^{-1}\right)$ in comparison with $\mathrm{Fe}_{3} \mathrm{O}_{4}$ NPs $\left(61\right.$ emug $\left.^{-1}\right)$ confirms the silica coating and formation of core/shell nanoparticles. Furthermore, a decreases in the magnetization value of the $\mathrm{Pd} @$ bisindole@ $\mathrm{SiO}_{2} @ \mathrm{Fe}_{3} \mathrm{O}_{4}$ (3) $\left(33.3\right.$ emug $\left.^{-1}\right)$, confirms the immobilization of organic groups on the surface.

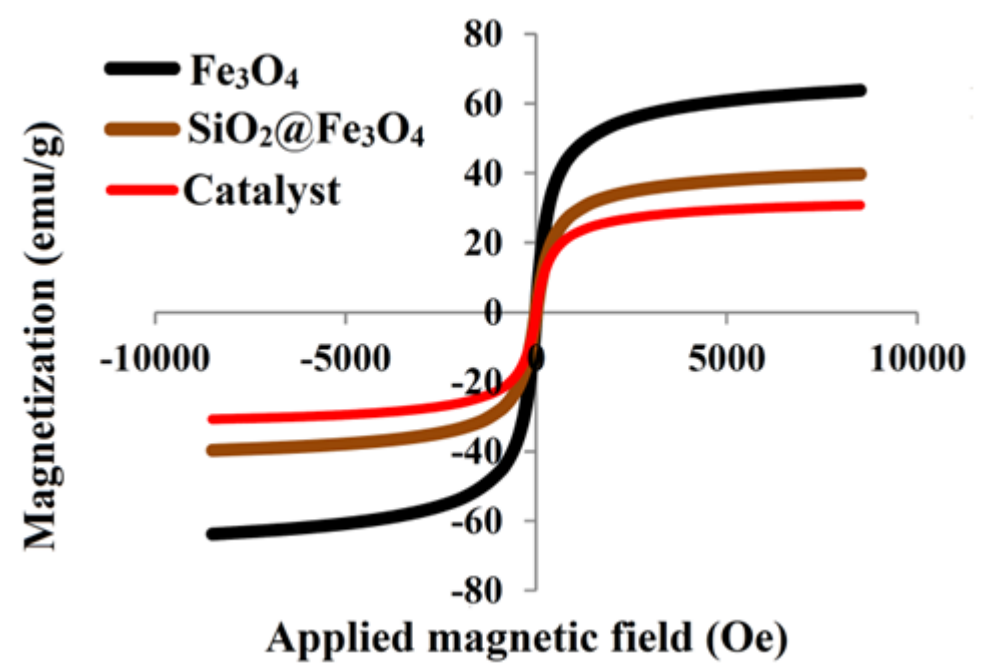

Figure 7. Magnetization curves of $\mathrm{Fe}_{3} \mathrm{O}_{4}, \mathrm{SiO}_{2} @ \mathrm{Fe}_{3} \mathrm{O}_{4}$, and $\mathrm{Pd} @$ bisindole@ $\mathrm{SiO}_{2} @ \mathrm{Fe}_{3} \mathrm{O}_{4}$ (catalyst).

The $\mathrm{N}_{2}$ adsorption-desorption isotherms for bisindole@ $\mathrm{SiO}_{2} @ \mathrm{Fe}_{3} \mathrm{O}_{4} \quad \mathrm{NPs}$ and Pd@bisindole@ $\mathrm{SiO}_{2} @ \mathrm{Fe}_{3} \mathrm{O}_{4}$ are presented in Figure 8 and the physical parameters measured with $\mathrm{N}_{2}$ sorption are summarized in Table 1 . The results indicated that both isotherms are of type IV according to IUPAC classification and exhibiting H3 hysteresis loop. The surface areas were calculated by Brunauer-Emmet-Teller (BET) method and are in the range of $31-39 \mathrm{~m}^{2} / \mathrm{g}$. Also, the pore size and pore volume were calculated by Barrett-Joyner-Halenda (BJH) method, the pore diameter were in between 25 and $31.5 \mathrm{~nm}$ with total pore volume in the range of $7-9 \mathrm{~cm}^{3} / \mathrm{g}$. These 
results indicated that surface area and pore volume increased after introducing palladium nanoparticles (Table 1). This may be related to palladium complex formation which caused an increase in the surface area and porosity of the catalyst.

Table 1. The BET surface area, BJH pore volume and pore size for bisindole@ $\mathrm{SiO}_{2} @ \mathrm{Fe}_{3} \mathrm{O}_{4} \mathrm{NPs}$ and $\mathrm{Pd} @$ bisindole@ $\mathrm{SiO}_{2} @ \mathrm{Fe}_{3} \mathrm{O}_{4}$

\begin{tabular}{llll}
\hline Sample & $\mathrm{S}_{\mathrm{BET}}\left(\mathrm{m}^{2} \mathrm{~g}^{-1}\right)$ & $\mathrm{V}_{\mathrm{t}}\left(\mathrm{cm}^{3} \mathrm{~g}^{-1}\right)$ & $\mathrm{D}_{\mathrm{BJH}}(\mathrm{nm})$ \\
\hline bisindole@SiO & & & \\
Pd@ $@ \mathrm{Fe}_{3} \mathrm{O}_{4} \mathrm{NPs}$ & 31 & 7.3 & 31.14 \\
& & & \\
& & 9.0 & 25.75 \\
\hline
\end{tabular}

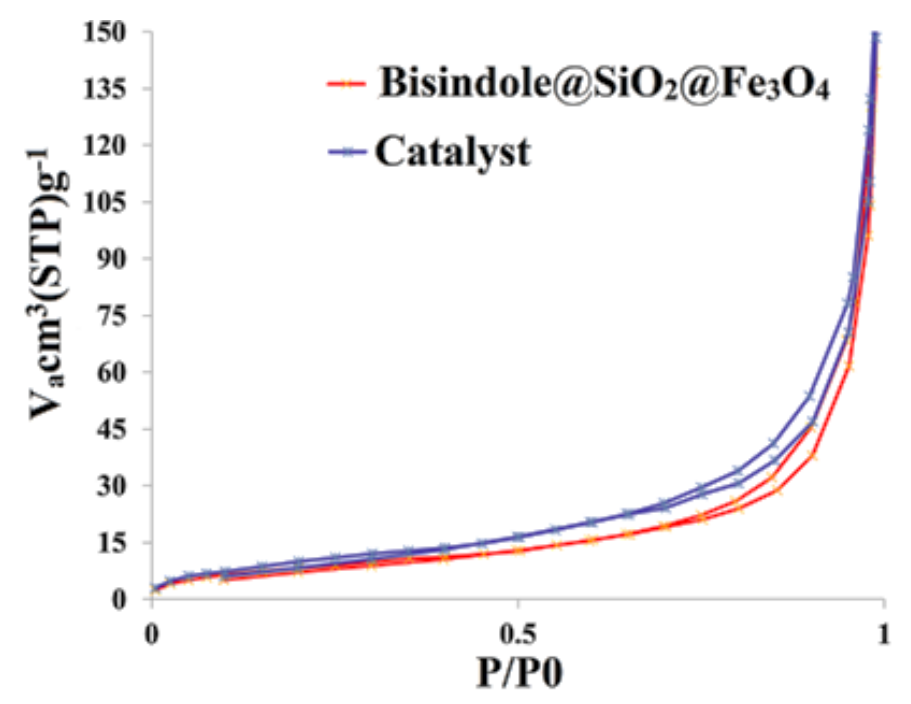

Figure 8. $\mathrm{N}_{2}$ adsorption/desorption isotherms of bisindole@ $\mathrm{SiO}_{2} @ \mathrm{Fe}_{3} \mathrm{O}_{4}$ and $\mathrm{Pd} @$ bisindole@ $\mathrm{SiO}_{2} @ \mathrm{Fe}_{3} \mathrm{O}_{4}$ (catalyst).

The catalytic activity of Pd@bisindole@ $\mathrm{SiO}_{2} @ \mathrm{Fe}_{3} \mathrm{O}_{4}$ was evaluated in Sonogashira-Hagihara reaction. Initial experiments with using iodobenzene and phenyl acetylene were performed to 
optimize the reaction conditions such as solvent type, temperature, and quantities of the base and catalyst (Table 2). As shown in Table 2, the reaction in distilled water in the presence of different bases resulted in low yields and only moderate yields were obtained using $\mathrm{Et}_{3} \mathrm{~N}, 1$,4-diazabicyclo [2.2.2] octane (DABCO), and ${ }^{i} \operatorname{Pr}_{3} \mathrm{~N}$ (Table 2, entries 2, 3 and 8). The use of inorganic salts as base did not improve reaction yields (Table 2, entries 1, 5-7). Reaction condition was also studied using organic bases in other solvents such as $\mathrm{CH}_{3} \mathrm{CN}$, DMF, THF, EtOH, toluene, DMA, PEG 200, and $\mathrm{H}_{2} \mathrm{O}-\mathrm{CH}_{3} \mathrm{CN}$ mixture. The best yields were obtained using DABCO as base and DMA as solvent at $60{ }^{\circ} \mathrm{C}$ (Table 2, entry 19). It is noticeable that when the reaction was carried out at room temperature, $18 \%$ drop in reaction yield was observed (Table 2, entry 20 ).

Table 2. Optimization of reaction condition for the coupling of iodobenzene and phenyl acetylene ${ }^{\mathrm{a}}$

\begin{tabular}{lccccc} 
& & & \\
\hline \\
1
\end{tabular}




\begin{tabular}{|c|c|c|c|c|c|}
\hline 6 & $t$-BuOK & $\mathrm{H}_{2} \mathrm{O}$ & 60 & 7 & 0.26 \\
\hline 7 & $\mathrm{NaOAc}$ & $\mathrm{H}_{2} \mathrm{O}$ & 60 & 2 & 0.52 \\
\hline 8 & $\mathrm{~N}(i-\mathrm{Pr})_{3}$ & $\mathrm{H}_{2} \mathrm{O}$ & 60 & 31 & 0.05 \\
\hline 9 & $\mathrm{NEt}_{3}$ & $\mathrm{CH}_{3} \mathrm{CN}$ & 60 & 82 & 0.02 \\
\hline 10 & $\mathrm{NEt}_{3}$ & DMF & 60 & 7 & 0.2 \\
\hline 11 & $\mathrm{NEt}_{3}$ & THF & 60 & 26 & 0.06 \\
\hline 12 & $\mathrm{NEt}_{3}$ & $\mathrm{EtOH}$ & 60 & 31 & 0.04 \\
\hline 13 & $\mathrm{NEt}_{3}$ & Toluene & 60 & 4 & 0.21 \\
\hline 14 & $\mathrm{NEt}_{3}$ & DMA & 60 & 5 & 0.35 \\
\hline 15 & $\mathrm{NEt}_{3}$ & $\mathrm{CH}_{3} \mathrm{CN} / \mathrm{H}_{2} \mathrm{O}$ & 60 & 53 & 0.02 \\
\hline 16 & $\mathrm{DABCO}$ & $\mathrm{CH}_{3} \mathrm{CN}$ & 60 & 90 & 0.02 \\
\hline 17 & $\mathrm{DABCO}$ & PEG200 & 60 & 68 & 0.02 \\
\hline 18 & $\mathrm{NEt}_{3}$ & PEG200 & 60 & 42 & 0.04 \\
\hline 19 & DABCO & DMA & 60 & 98 & 0.01 \\
\hline 20 & DABCO & DMA & 30 & 80 & 0.01 \\
\hline
\end{tabular}

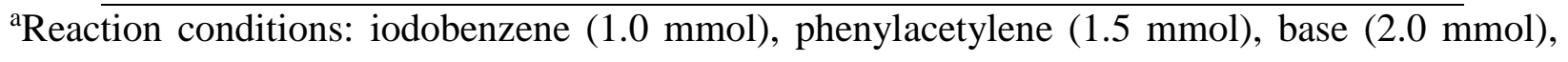
solvent ( $1.5 \mathrm{~mL}$ ), catalyst ( $4.0 \mathrm{mg}$, containing $0.18 \mathrm{~mol} \% \mathrm{Pd}) .{ }^{\mathrm{b}}$ Yield determined by GC analysis.

${ }^{\mathrm{c}}$ The relative standard deviation (error bars) was obtained from three independent reactions. 
With the optimized reaction conditions in hand, the substrate scope of the Sonogashira-Hagihara reaction was evaluated for the reaction of structurally diverse aryl halides and acetylenes in the presence of Pd@bisindole@ $\mathrm{SiO}_{2} @ \mathrm{Fe}_{3} \mathrm{O}_{4}$ (Table 3). The reaction of both electron-rich and electron-poor aryl iodides with phenylacetylene gave the corresponding products in high to excellent yields (Table 3, entries 1-8). The reaction of 2-iodothiophene as a heterocyclic aryl iodide with 4-ethynyltoluene afforded the desired product in 99\% yield (Table 3, entry 3). The catalytic scope of Pd@bisindole@ $\mathrm{SiO}_{2} @ \mathrm{Fe}_{3} \mathrm{O}_{4}$ was also investigated for the reaction of various aryl bromides with terminal alkynes. As expected, aryl iodides were more reactive than aryl bromides, and the substituent effects in aryl iodides appeared to be less significant than in aryl bromides. Results showed that both activated aryl bromides such as 1-bromo-4-nitrobenzene, 4bromobenzaldehyde, 4-bromobenzonitrile, 4-bromoacetophenon, 1-bromo-, 4-fluorobenzene and unactivated aryl bromides such as bromobenzene, 4-bromoanisole, 1-bromonaphtalene reacted well and the corresponding internal alkynes were obtained in high yields. Reaction of 1-bromo-4chlorobenzene and 4-bromonitrobenzene with propargyl alcohol also provided desired coupling products in excellent yields (Table 3, entries 21 and 22). However, less reactive 4chloronitrobenzene under optimized reaction conditions resulted in $39 \%$ of the desired product. However, the same reaction as well as the reaction of 4-chlorobenzaldehyde, 4-chlorobenzonitrile with phenylacetylene at elevated temperature $\left(120^{\circ} \mathrm{C}\right)$ in the presence of TBAB and $0.36 \mathrm{~mol} \%$ of palladium catalyst gave corresponding products in high to excellent yields (Table 3, entries 2326). Based on the coupling results represented in Table 3, the Pd catalyst developed in this study, efficiently catalyzed the reaction of different aryl halides with alkynes under air with reproducible, high turnover and frequency numbers, and copper-free conditions. It is worth mentioning that 
obtained standard deviation (error bars) from four independent replicate experiments were less than 0.4.

Table 3. Copper-free and phosphane-free Sonogashira-Hagihara reactions of terminal alkynes with aryl halides ${ }^{\text {a }}$

$$
\mathrm{ArX}+\mathrm{R}=\frac{\text { Catalys }(0.18-0.36 \mathrm{~mol} \%)}{\mathrm{DABCO}, 60-120^{\circ} \mathrm{C}} \mathrm{Ar}=\mathrm{DMA}
$$

Entry


4<smiles>Cc1ccc(I)cc1</smiles>

$\mathrm{C}_{6} \mathrm{H}_{5} \quad 24$<smiles>Cc1ccc(C#Cc2ccccc2)cc1</smiles>

5<smiles>COc1ccc(I)cc1</smiles>

$\mathrm{C}_{6} \mathrm{H}_{5}$

$\mathrm{C}_{6} \mathrm{H}_{5}$<smiles>Fc1ccc(I)cc1</smiles><smiles>Clc1ccc(I)cc1</smiles>

$\mathrm{C}_{6} \mathrm{H}_{5}$

12<smiles>Clc1ccc(C#Cc2ccccc2)cc1</smiles>

$\mathrm{C}_{6} \mathrm{H}_{5}$<smiles>O=[N+]([O-])c1ccc(I)cc1</smiles>

$\mathrm{C}_{6} \mathrm{H}_{5} \quad 6$<smiles>O=[N+]([O-])c1ccc(C#Cc2ccccc2)cc1</smiles>

$\mathrm{C}_{6} \mathrm{H}_{5} \quad 24$

9<smiles>COc1ccc(Br)cc1</smiles>

93

$555 / 61.3 \quad 0.011$

$100^{\mathrm{e}}$

$544 / 72.2 \quad 0.015$

98

$544 / 71.4 \quad 0.015$

98

$527 / 83.1 \quad 0.013$

95

$394 / 42.1 \quad 0.014$<smiles>COc1ccc(C#Cc2ccccc2)cc1</smiles> 
10<smiles>Brc1ccccc1</smiles>

$\mathrm{C}_{6} \mathrm{H}_{5}$

24<smiles>C(=Cc1ccccc1)c1ccccc1</smiles>

11<smiles>Brc1cncnc1</smiles>

$\mathrm{C}_{6} \mathrm{H}_{5}$

24<smiles>C(=Cc1cncnc1)c1ccccc1</smiles>

$\mathrm{C}_{6} \mathrm{H}_{5} \quad 24$<smiles>C(#Cc1ccccn1)c1ccccc1</smiles>

$\mathrm{C}_{6} \mathrm{H}_{5} \quad 24$<smiles>N#Cc1ccc(C=Cc2ccccc2)cc1</smiles><smiles>N#Cc1ccc(Br)cc1</smiles><smiles>O=Cc1cccc(Br)c1</smiles>

14

$\mathrm{C}_{6} \mathrm{H}_{5} \quad 24$<smiles>O=Cc1cccc(C#Cc2ccccc2)c1</smiles>

$\mathrm{C}_{6} \mathrm{H}_{5}$

24

15<smiles>O=Cc1ccc(Br)cc1</smiles>

94

$438 / 53.8 \quad 0.38$

79

$555 / 61.1 \quad 0.011$

$100^{\mathrm{e}}$

$555 / 60.3 \quad 0.013$

$100^{\mathrm{e}}$

$544 / 40.6 \quad 0.021$

98

$522 / 64.8 \quad 0.3$

$550 / 66.7 \quad 0.012$<smiles>O=Cc1ccc(C#Cc2ccccc2)cc1</smiles> 
16<smiles>O=Cc1ccc(Br)cc1</smiles>

4-

$\mathrm{MeC}_{6} \mathrm{H}_{4}$

17<smiles>O=[N+]([O-])c1ccc(Br)cc1</smiles>

$\mathrm{C}_{6} \mathrm{H}_{5}$

24<smiles>O=[N+]([O-])c1ccc(C=Cc2ccccc2)cc1</smiles>

18<smiles>Fc1ccc(Br)cc1</smiles>

$\mathrm{C}_{6} \mathrm{H}_{5}$

24<smiles>Fc1ccc(C=Cc2ccccc2)cc1</smiles>

$\mathrm{C}_{6} \mathrm{H}_{5} \quad 24$<smiles>CC(=O)c1ccc(C#Cc2ccccc2)cc1</smiles>

$\mathrm{C}_{6} \mathrm{H}_{5}$

24<smiles>C(#Cc1cccc2ccccc12)c1ccccc1</smiles>

$\mathrm{HOCH}_{2-} \quad 24$

21<smiles>OCCO</smiles><smiles>OCC#Cc1ccc(Cl)cc1</smiles>

$516 / 67.9 \quad 0.039$

93

$544 / 75.9 \quad 0.013$

98

$522 / 72.3 \quad 0.017$

94

$527 / 66.5 \quad 0.019$

95

$483 / 50.4 \quad 0.021$

87

$533 / 57.4 \quad 0.02$ 
22<smiles>O=[N+]([O-])c1ccc(Br)cc1</smiles>

$\mathrm{HOCH}_{2-} \quad 24$<smiles>O=[N+]([O-])c1ccc(C#CCO)cc1</smiles>

$\mathrm{C}_{6} \mathrm{H}_{5}$

48<smiles>C(#Cc1ccccc1)c1ccccc1</smiles>

$\mathrm{C}_{6} \mathrm{H}_{5} \quad 48$<smiles>O=Cc1ccc(C#Cc2ccccc2)cc1</smiles>

$\mathrm{C}_{6} \mathrm{H}_{5}$

48<smiles>O=[N+]([O-])c1ccc(C#Cc2ccccc2)cc1</smiles>

$\mathrm{C}_{6} \mathrm{H}_{5} \quad 48$<smiles>N#Cc1ccc(Cl)cc1</smiles><smiles>N#Cc1ccc(C#Cc2ccccc2)cc1</smiles>

$533 / 62.3 \quad 0.018$ 96

$172.2 / 10.9 \quad 0.029$ $62^{\mathrm{e}, \mathrm{f}}$

$252 / 18.5 \quad 0.018$

$91^{\mathrm{f}}$

$247 / 16.2 \quad 0.015$

$89^{\mathrm{f}}$

$236 / 14.4 \quad 0.013$

$85^{\mathrm{f}}$

aReaction conditions: ArX (1 mmol), alkyne (1.5 mmol), DABCO (1.5 mmol), catalyst $(0.18$ mol\%), DMA (2 mL); ${ }^{\mathrm{b}}$ Isolated yields; ${ }^{\mathrm{C}} \mathrm{TOF}$ are after $6 \mathrm{~h}$ from starting of the reactions; ${ }^{\mathrm{d}}$ The relative standard deviation (error bars) was obtained from four independent reactions; ${ }^{\mathrm{e}} \mathrm{GC}$ yields; ${ }^{\mathrm{f} U}$ sing $1.0 \mathrm{mmol}$ TBAB. 
In order to demonstrate the practical application of Pd@bisindole@ $\mathrm{SiO}_{2} @ \mathrm{Fe}_{3} \mathrm{O}_{4}$, reaction of iodobenzene with phenylacetylene was scaled up to $10 \mathrm{mmol}$ under optimized reaction conditions. Results showed that reaction proceed efficiently and produced desired product in $89 \%$ isolated yield after $24 \mathrm{~h}$.

In order to assess the catalytic system changes, we made careful kinetic monitoring of the reaction of 5-bromopyrimidine with phenylacetylene under different reaction conditions. Under optimized reaction condition, it proceeded smoothly without induction period and was completed during 24 h period (Figure 9, a). Lower amounts of catalyst loading (0.02 and 0.01) caused a decrease in the reaction yield compared to standard reaction under optimized conditions (Figure 9, b,c). However, an increase in the catalyst amount to 0.36 caused an increase in reaction rate and completion of the reaction faster (Figure 9, d).

To confirm the heterogeneous nature of the active catalyst introduced in this study, some catalytic reactions were performed in the presence of excess $\mathrm{Hg}(0)$ as catalyst poison (molar ratio to $[\mathrm{Pd}]$ 400). As shown in Figure $(9$, e), reaction rate was strongly suppressed. It is well known that $\operatorname{Hg}(0)$ can poison heterogeneous catalysts by amalgamating the metal or adsorbing on the metal surface. On the other hand, $\operatorname{Hg}(0)$ has no poisoning effect on molecular homogeneous (ligand-protected) Pd species. Poly(vinylpyridine)(PVPy) is another catalyst poising agent and scavenger for soluble molecular $\mathrm{Pd}$ and soluble $\mathrm{Pd}(0)$ nanoparticles. The catalytic reactions were conducted in the presence of an excess amount of PVPy (molar ratio to $[\mathrm{Pd}] \sim 400$ ) and the results showed no change in reaction rate and it proceeded similar to standard optimized conditions, confirming heterogeneous nature of the catalyst (Figure 9, f) [56,57]. 


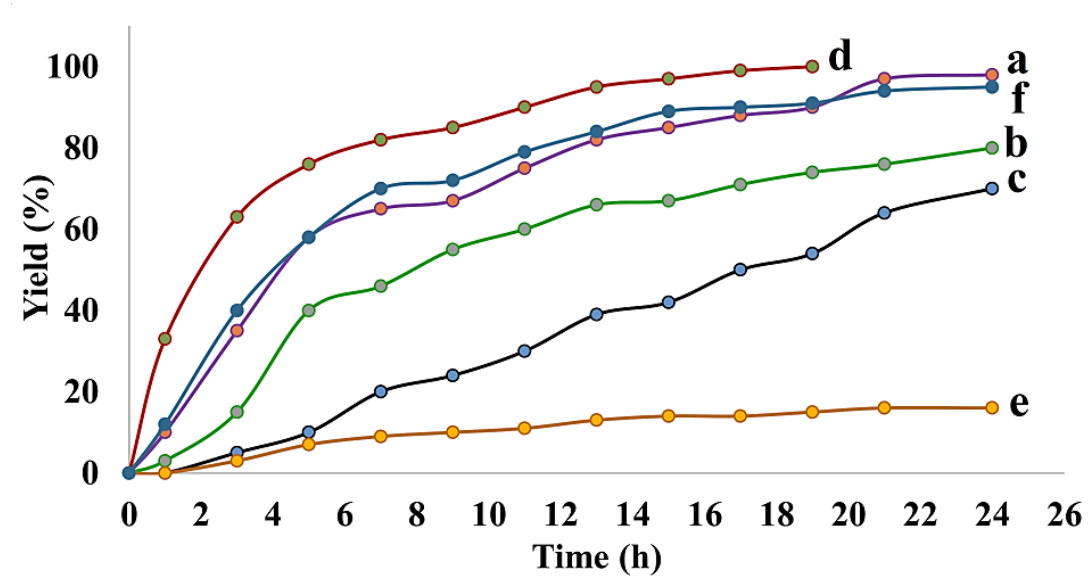

Figure 9. Kinetic monitoring of the reaction of 5-bromopyrimidine with phenylacetylene under different reaction conditions: (a) reaction under optimized reaction conditions, (b) using 0.02 mol\% Pd catalyst, (c) using $0.01 \mathrm{~mol} \%$ Pd catalyst, (d) using $0.36 \mathrm{~mol} \% \mathrm{Pd}$ catalyst, (e) reaction in the presence of an excess $\operatorname{Hg}(0)$, (f) reaction in the presence of an excess amount of PVPy

Further information about homogeneous or heterogeneous nature of the catalyst was obtained by hot filtration test for the reaction of iodobenzene and phenylacetylene. After $5 \mathrm{~h}$ with $54 \%$ conversion to desired product, the reaction mixture was filtered and filtrate was allowed to react for $24 \mathrm{~h}$. GC analysis after $24 \mathrm{~h}$ showed $65 \%$ conversion to desired coupling product. This result also confirms that using this catalyst reaction proceeds mostly under heterogeneous conditions.

One of the main factors sought in designing any catalyst system, especially for practical industrial scale reactions is the recyclability of the catalyst. This factor was measured for our palladium

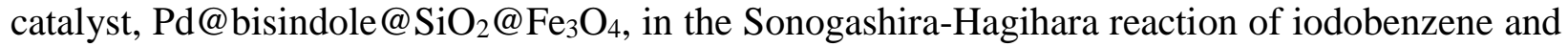
phenylacetylene. After completion of the reaction, the magnetic catalyst was easily recovered from the reaction mixture by an external magnet and after water/diethyl ether wash, it was reused in another coupling reaction. Results indicated that the catalyst can be effectively used at least during seven consecutive runs without a significant loss of activity, confirming reproducibility of results 
(Figure 10). It is notable that leaching of Pd into the reaction mixture after first run was determined to be $1 \%$ (ICP analysis), confirming the obtained results from poisoning and hot filtration tests.

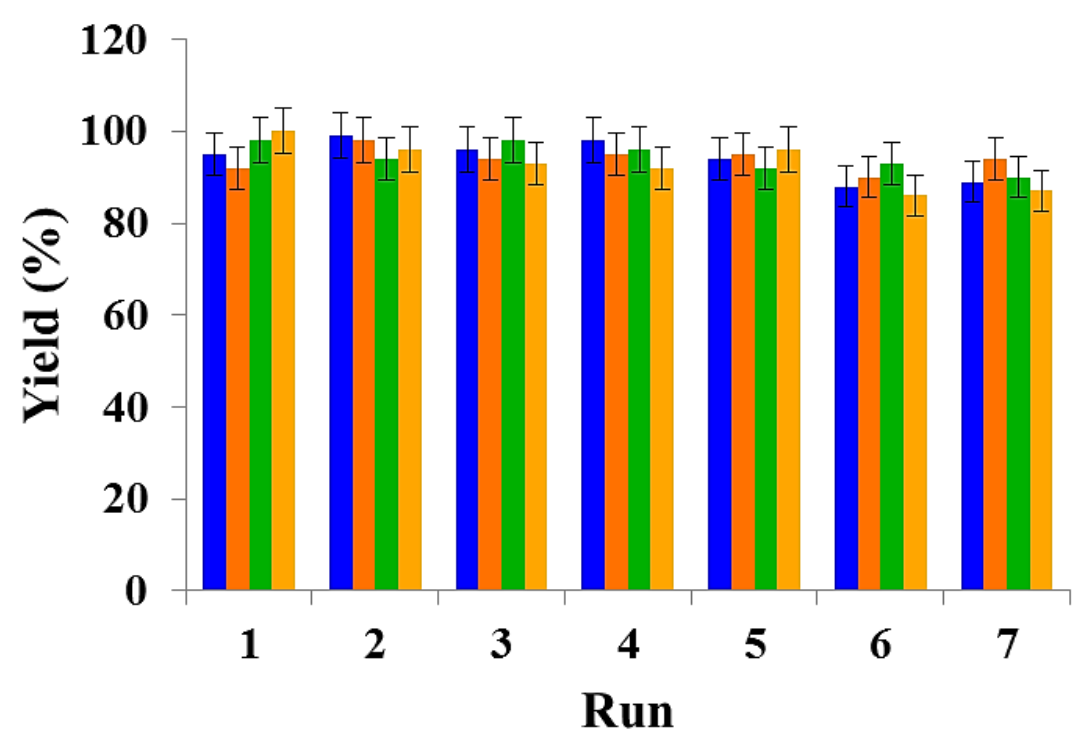

Figure 10. Successive reaction runs and GC yields for the reaction of iodobenzene with phenylacetylene with $\mathrm{Pd} @$ bisindole $@ \mathrm{SiO}_{2} @ \mathrm{Fe}_{3} \mathrm{O}_{4}$ (Error bars show standard deviation from four separate experiments).

TEM image of the catalyst after three runs, shown in Figure 11, reveals that Pd@bisindole@ $\mathrm{SiO}_{2} @ \mathrm{Fe}_{3} \mathrm{O}_{4}$ preserves its original structure after each reaction. 


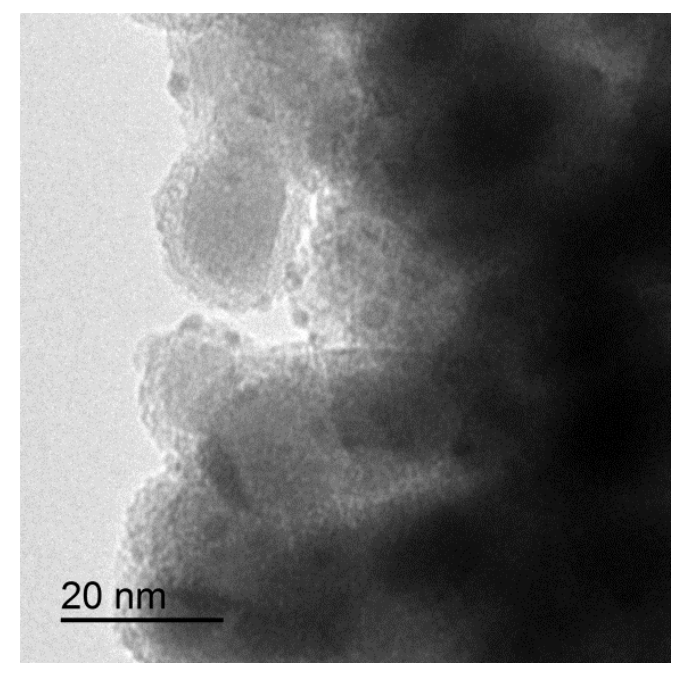

Figure 11. TEM image of the recovered $\mathrm{Pd} @$ bisindole@ $\mathrm{SiO}_{2} @ \mathrm{Fe}_{3} \mathrm{O}_{4}$ after three runs.

Superparamagnetic property of the catalyst and recovered catalyst after $3^{\text {rd }}$ run was also measured and results indicate that magnetization of the catalyst is decreased slightly after each reaction run (Figure 12).

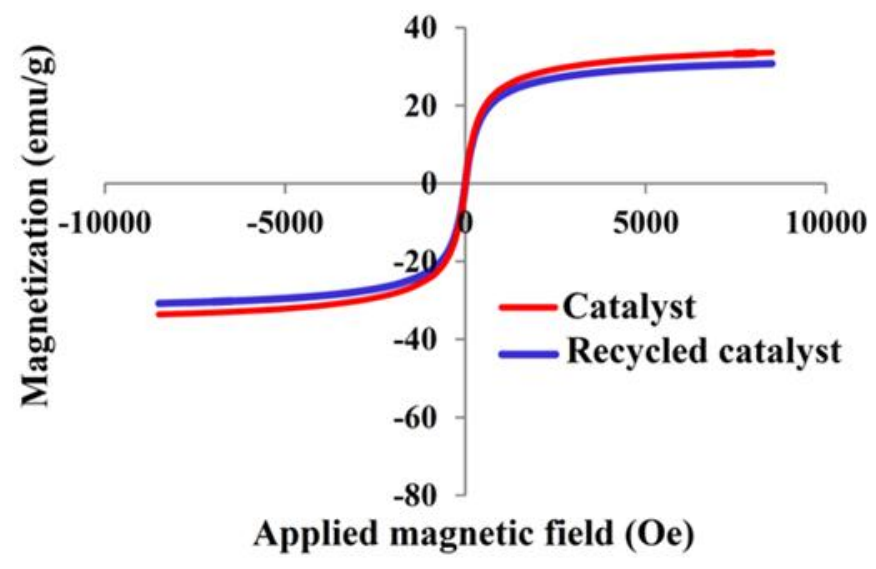

Figure 12. Magnetization curves for $\mathrm{Pd} @$ bisindole@ $\mathrm{SiO}_{2} @ \mathrm{Fe}_{3} \mathrm{O}_{4}$ and its recycled form after $3^{\text {rd }}$ run. 
Furthermore, XPS analysis of Pd@bisindole@ $\mathrm{SiO}_{2} @ \mathrm{Fe}_{3} \mathrm{O}_{4}$ after three run showed the presence of the related peaks for both $\mathrm{Pd}(0)$ and $\mathrm{Pd}(\mathrm{II})$ at $335-340$ and 337-342 $\mathrm{eV}$, respectively (Figure $13)$.

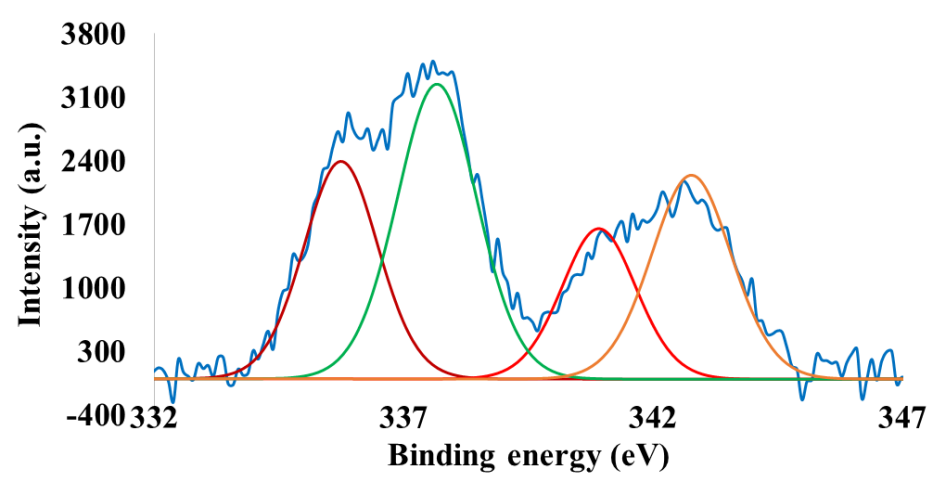

Figure 13.XPS spectrum of the recycled Pd@bisindole@ $\mathrm{SiO}_{2} @ \mathrm{Fe}_{3} \mathrm{O}_{4}$ after $3^{\text {rd }}$ run

\section{Conclusion}

In conclusion, palladium supported on Bis(indolyl)methane functionalized magnetite nanoparticles, a new magnetically separable catalyst, has been prepared, characterized and successfully applied as catalyst in Sonogashira-Hagihara reaction. Aryl iodides and bromides were reacted efficiently under air and copper-free conditions with different alkynes by using $0.18 \mathrm{~mol}$ $\%$ of this catalyst at $60{ }^{\circ} \mathrm{C}$. These reactions afforded desired products in high to excellent yields with high TON and the error bars were less than 0.4. Aryl chlorides were also reacted at $120{ }^{\circ} \mathrm{C}$ using TBAB additive. Negiligilibe leaching of Pd and hot filteation tests showed the heterogeneous nature of the catalyst under reaction conditions. Kinetic monitoring of the reaction of 2 bromopipyridine with phenylacetylene under different reaction conditions showed important effects of catalyst quantity in reaction rate. Also, the application of two general poisoning agents 
$(\mathrm{Hg}(0)$, PVPy $)$ confirmed heterogeneous nature of catalyst during catalytic reactions. Main advantages of this new catalyst system are its simple recoverability by use of an external magnet and its effecgtive recyclability. The results show that a four layer heterogenous system introduced in this work can be used as catalyst in seven consecutive catalytic reaction runs with negligible decrease in its activity. This was carried out through 4 times repetition of each of seven runs, emphasizing its reproducibility. Besides, TEM, XPS and VSM analyses of the recovered catalyst suggest that the catalyst's originl shape is maintained during reaction. Results from coupling reaction of a series of selected aryl halides and alkynes show comparatively improved yields of Sonogashira-Hagihara cross-coupling in air and at lower temperatures in the presence of a recoverable catalyst system introduced in this study.

\section{Acknowledgment}

The authors thank Institute for Advanced Studies in Basic Sciences (IASBS) Research Council and Iran National Science Foundation (INSF-Grant number: 94010666) for financial support of this work. C. Nájera is also thankful to The Spanish Ministerio de Economia y Competitividad (MINECO) (projects CTQ2013-43446-P and CTQ2014-51912-REDC), FEDER, the Generalitat Valenciana (PROMETEOII/2014/017) and the University of Alicante for financial support. 


\section{References}

[1] Á. Molnár, Palladium-Catalyzed Coupling Reactions: Practical Aspects, Future Developments, Wiley-VCH Verlag, Weinheim, 2013.

[2] M. Lamblin, L. Nassar-Hardy, J.-C. Hierso, E. Fouquet, F.-X. Felpin, Adv. Synth. Catal. 352 (2010) 33-79.

[3] K. Sonogashira, Y. Tohda, N. Hagihara, Tetrahedron Lett. 16 (1975) 4467-4470.

[4] R. Chinchilla, C. Nájera, Chem. Rev. 107 (2007) 874-922.

[5] R. Chinchilla, C. Nájera, Chem. Soc. Rev. 40 (2011) 5084-5121.

[6] M. M. Heravi, S. Sadjadi, Tetrahedron. 65 (2009) 7761-7775.

[7] A. Kollhofer, H. Plenio, Chem. Eur. J. 9 (2003) 1416-1425.

[8] R. Ciriminna, V. Pandarus, G. Gingras, F. Béland, P. D. Carà, M. Pagliaro, ACS Sustainable Chem. Eng. 1 (2013) 57-61.

[9] F. Bellina, M. Lessi, Synlett. 23 (2012) 773-777.

[10] F. Wagner, D. Comins, J. Org. Chem. 71 (2006) 8673-8675.

[11] S. Frigoli, C. Fuganti, L. Malpezzi, L. Serra, Org. Proc. Res. Dev. 9 (2005) 646-650.

[12] K. C. Nicolaou, W.-M. Dai, Angew. Chem. Int. Ed. 30 (1991) 1387-1416.

[13] P. Siemsen, R. C. Livingston, F. Diederich, Angew. Chem. Int. Ed. 39 (2000) 2632-2657. 
[14] J. Jover, P. Spuhler, L. Zhao, C. McArdle and F. Maseras, Catal. Sci. Technol. 4 (2014) 4200-4209.

[15] J. F. Cívicos, D. A. Alonso, C. Nájera, Adv. Synth. Catal. 355 (2013) 203-205.

[16] H. Zhong, J. Wang, L. Li, R. Wang, Dalton Trans. 43 (2014) 2098-2103.

[17] S. Das, S. Samanta, S. Raya, P. Biswas, RSC Adv. 5 (2015) 75263-75267.

[18] V. Singh, R. Ratti, S. Kaur, J. Mol. Catal. A Chem. 334 (2011) 13-19.

[19] E. A. Savicheva, D. V. Kurandina, V. A. Nikiforov, V. P. Boyarskiy, Tetrahedron Lett. 55 (2014) 2101-2103.

[20] H. Firouzabadi, N. Iranpoor, F. Kazemi, M. Gholinejad, J. Mol. Catal. A Chem. 357 (2012) 154-161.

[21] J. Zhang, M. Dakovic, Z. Popovic, H. Wu, Y. Liu, Catal. Commun. 17 (2012) 160-163.

[22] M. Gholinejad, F. Hamed, P. Biji, Dalton Trans. 44 (2015) 14293-14303.

[23] L. Yang, P. Guan, P. He, Q. Chen, C. Cao, Y. Peng, Z. Shi, G. Pang, Y. Shi, Dalton Trans. 41 (2012) 5020-5025.

[24] M. García-Melchor, M. C. Pacheco, C. Nájera, A. Lledós, G. Ujaque, ACS Catal. 2 (2012) $135-144$.

[25] D. Wang, D. Denux, J. Ruiz, D. Astruc, Adv. Synth. Catal. 355 (2013) 129-142.

[26] A. Modak, J. Mondal, A. Bhaumik, Green Chem. 14 (2012) 2840-2855.

[27] M. Zeng, X. Yuan, S. Zuo, C. Qi, RSC Adv. 5 (2015) 37995-38000. 
[28] M. Pagliaro, V. Pandarus, F. Béland, R. Ciriminna, G. Palmisano, P. D. Carà, Catal. Sci. Technol. 1 (2011) 736-739.

[29] M. Bakherad, A. Keivanloo, B. Bahramian, S. Jajarmi, Appl. Catal. A Gen. 2010, 506, 237245.

[30] T. Cheng, D. Zhang, H. Li, G. Liu, Green Chem. 16 (2014) 3401-3427.

[31] V. Polshettiwar, R. Luque, A. Fihri, H. Zhu, M. Bouhrara, J.-M. Basset, Chem. Rev. 111 (2011) 3036-3075.

[32] R. Varma, Sustain. Chem. Process 2 (2014) 11-17.

[33] B. Karimi, F. Mansouri, H. Mirzaei, ChemCatChem. 7 (2015) 1736-1789.

[34] S. Shylesh, L. Wang, W. R. Thiel, Adv. Synth. Catal. 352 (2010) 425-432.

[35] B. Karimi, F. Mansouri, H. Vali, Green Chem. 16 (2014) 2587-2596.

[36] M. Gholinejad, M. Razeghi, A. Ghaderi, P. Biji, Catal. Sci. Technol. 6 (2016) 3117-3127.

[37] M. Gholinejad, V. Karimkhani, I. Kim, Appl. Organomet. Chem. 28 (2014) 221-224.

[38] B. P. Morgan, G. A. Galdamez, R. J. Gilliard and R. C. Smith, Dalton Trans. (2009) 20202028.

[39] Y-B. Zhou, Z-X. Xi, W-Z. Chen, D-Q. Wang, Organometallics, 27 (2008) 5911-5920.

[40] M. Gholinejad, M. Razeghi, C. Najera, RSC Adv. 5 (2015) 49568-49576.

[41] M. Gholinejad, M. Seyedhamzeh, M. Razeghi, C. Najera, M. Kompany-Zareh, ChemCatChem, 8 (2016), 441-447. 
[42] S. Sobhani, Z. Zeraatkar, F. Zarifi, New J. Chem. 39 (2015) 7076-7085.

[43] S. Natour, R. Abu-Reziq, ChemCatChem, 7 (2015) 2230-2240.

[44] M. Esmaeilpour, J. Javidi, A. Mokhtari, Mehdi, F. Nowroozi Dodeji, J. Iran Chem. Soc. 11 (2014) 499-510.

[45] P. Li, L. Wang, L. Zhang, G.-W. Wang, Adv. Synth. Catal. 354 (2012) 1307-1318.

[46] M. Kim, H. Kang, K. H. Park, Cat. Commun. 72 (2015) 150-155.

[47] W. Li, X. Jia, B. Zhang, L. Tian, X. Li, H. Zhang, Q. Zhang, New J. Chem. 39 (2015) 29252934.

[48] M. Nasrollahzadeh, S. M. Sajadi, A. Rostami-Vartooni, M. Khalaj, J. Mol. Catal. A Chem. 396 (2015) 31-39.

[49] M. Esmaeilpour, A. R. Sardariana, J. Javidi, J. Organomet. Chem. 749 (2014) 233-240.

[50] J. Chung, J. Kim, Y. Jang, S. Byun, T. Hyeon, B. M. Kim, Tetrahedron Lett. 54 (2013)

[51] R. Massart, IEEE Trans. Magn. 17 (1981) 1247-1248.

[52] J. Sun, Y. Fu, G. He, X. Sun, X. Wang, Catal. Sci. Technol. 4 (2014) 1742-1748.

[53] Z. H. Zhang, L. Yin, Y. M. Wang, Synthesis. (2005) 1949-1954.

[54] D. Astruc, F. Lu, J. R. Aranzaes, Angew. Chem. Int. Ed. 44 (2005) 7852-7872.

[55] Q. Zhang, H. Su, J. Luo, Y. Wei, Catal. Sci. Technol. 3 (2013) 235-243. 
[56] K. Yu, W. Sommer, J. M. Richardson, M. Weck, C. W. Jones, Adv. Synth. Catal. 347 (2005) 161-171

[57] B. Karimi, P. Fadavi Akhavan, Inorg. Chem. 50 (2011) 6063-6072. 
Palladium Supported on Bis(indolyl)methane Functionalized Magnetite Nanoparticles as an Efficient Catalyst for Copper-Free Sonogashira-Hagihara Reaction

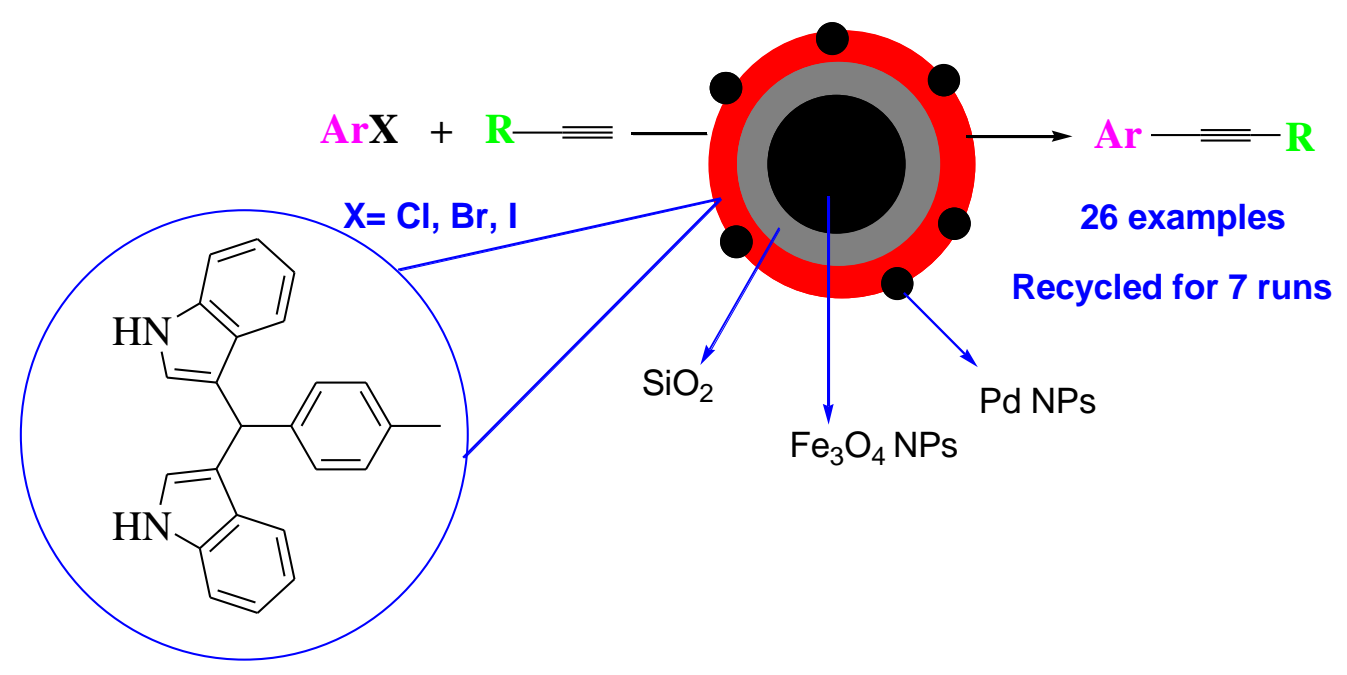

